\title{
Voltage Standardization of DC Distribution System for Residential Buildings
}

\author{
R. K. Chauhan, B. S. Rajpurohit, R. E. Hebner, S. N. Singh, and F. M. Gonzalez-Longatt
}

\begin{abstract}
The renewable energy sources (RES) such as photovoltaic (PV) are basically DC power sources. In the present scenario, the integration of RES to power distribution infrastructure necessitates the DC-AC converter. Moreover the DC loads in the buildings is ever increasing with the use of CFL, LED, refrigerator, TV, fan, air conditioner, laptop, and other electronics in workplaces and homes. This forced to introduce the internal or external AC-DC converter to tie the DC load to AC distribution infrastructure of existing power system. This is further adding losses and complexity. This AC-DC converter stage can be reduces up to a certain level by $\mathrm{DC}$ distribution system (DCDS). Secondly the multi voltage rating of RES and DC load insists to introduce DC-DC converter in DCDS infrastructure. This will further add losses and complexity. In this paper a standard voltage level DCDS is proposed to minimize the system losses, complexity. To verify the simulated results in terms of building load and converter losses, a DCDS equipped with different energy sources like solar panel (PV), public utility (PU) and battery bank (BB) is compared with ACDS.
\end{abstract}

Index Terms-DC distribution system, DC appliances, voltage level, conversion losses, DC Microgrid.

\section{INTRODUCTION}

Due to increasing demand and environment concern, the integration of renewable energy source (RES) to power system is increasing day by day. The RES such as solar, wind turbine, fuel cells are intrinsically DC power sources. This necessitates the introduction of DC-AC converter at generation end, thereby adding conversion losses and complexity [1]. Secondly, in last two decays, the continuously increments in the development of DC appliances is decreasing the building load but insists to introduce AC-DC converter and increase the conversion loss and complexity of the system [2]. Moreover the DC systems are free from inductance, skin effect, dielectric losses, and interference with communication system. The absence of inductance in DC system makes voltage drop very low. While the absence of skin effect the small cross section conductor is required in DC system comparing with AC. This reduces the line conductor weight.

Manuscript received July 8, 2014; revised May 23, 2015.

R. K. Chauhan and B. S. Rajpurohit are with the School of Computing and Electrical Engineering, Indian Institute of Technology Mandi, HP-175001, India (e-mail: rajeevchr_nitj@yahoo.com, bsr@iitmandi.ac.in).

R. E. Hebner is with Center for Electromechanics, University of Texas at Austin, Austin, TX 78758 USA (e-mail: r.hebner@cem.utexas.edu).

S. N. Singh is with the Department of Electrical Engineering, Indian Institute of Technology Kanpur, UP 208002, India (e-mail: snsingh@gmail.com).

F. M. Gonzalez-Longatt is with Electrical Power System at School of Electronic, Electrical and Systems Engineering, Loughborough University, UK (e-mail: F.Gonzalez-Longatt@ @lboro.ac.uk).
The DC lines also have very low corona losses. The voltage stress in DC system is as follows;

$$
V_{d c}=\sqrt{2} \times V_{a c}
$$

where $V_{d c}$ is the DC system voltage and $V_{a c}$ is the AC system voltage.

According to eq.(1), the DC system has a less potential stress over AC system for same voltage. For example if a system is designed for $230 \mathrm{~V} \mathrm{AC}$, it can bear $325 \mathrm{~V} \mathrm{DC}$ without any rapture in insulation. This helps to reduce the gap between two conductors of the distributed line. The less potential stress and weight of conductor reduce the size of the tower and insulator. This decreases the cost of the system and makes the system more economical. On the other hand due to absence of capacitance in the DC systems these are having very low charging current and decrease power losses in the line. This motivates to re-design the AC system into DC system. The DCDS has well known advantages over ACDS in terms of requirement of fewer amounts of material, low losses, efficiency and cost etc. [3], [4]. The DC power systems special applications as telecommunication systems [5], electric vehicles, shipboard systems [6], traction [7], [8] has been discussed in literature. In [9], the performance of a low voltage direct current (LVDC) and $230 \mathrm{~V}$ AC systems has been analyzed by considering line losses, devices internal losses, new wire cost and energy consumption cost. In [10], three $20 \mathrm{~V}, 230 \mathrm{~V}$ and $325 \mathrm{~V}$ DC voltage level has been analyzed for residential buildings by considering the public utility as a main power source. Additional benefits of DC microgrids are that they produce less heat inside the building envelope so theses are more efficient.

A number of studies have done on several issues of residential DCDS. The majority of studies have purely analytical in nature, involving no demonstrations or laboratory measurements. In [11] the potential energy savings has been estimated by replacing AC-DC converters with a more efficient centralized rectifier (that converts AC power coming from the grid to DC) and using DC distribution within the house to power DC-internal loads. The author assumed 70-75\% efficiency for AC-DC converters and $90 \%$ efficiency for the centralized rectifier and accounted for some efficiency improvements from switching from AC-powered to DC-internal appliances, such as refrigerators. In [12] author created a model that compared DC versus AC distribution in a residential building with and without an on-site DC power source. In addition, in [13] a model has been proposed that estimated the costs and energy use of residential power distribution for five scenarios, including AC distribution, 
hybrid AC and DC distribution, and DC distribution for various voltage levels. They concluded that for all scenarios including DC distribution, energy efficiency and costs were improved. It should be mentioned that this study assumed high DC voltages $(220 \mathrm{~V}-750 \mathrm{~V})$ and power conversion efficiencies that favored DC distribution. In [14] the increasing use of DC-internal home appliances and proposed a hybrid DC and AC power system that included energy storage and allowed for DC generation from solar cells have been proposed. Calculation for the conduction losses within a house with DC distribution at different line voltages has been done and findings showing that very small efficiency benefits can be achieved with DC distribution (depending online voltages). Like in [12], recommend DC distribution in residential buildings is not recommended in [15], unless on-site DC power generation is available. While residential demonstration products are currently under discussion, in [16] only published demonstration-type project for residential buildings have been explored. The researchers constructed a mini residential power system with a combination of a $5 \mathrm{~kW}$ $\mathrm{PV}$ array, a $2.4 \mathrm{~kW}$ fuel cell, and a $400 \mathrm{~W}$ wind turbine as DC energy sources supplying direct-DC to $12 \mathrm{~V}$ and $24 \mathrm{~V}$ DC-internal loads. The authors projected that the use of micro-DC distribution systems will be more widespread as the share of DC devices increases in the future. The DC voltage range for versatile DC system setups can be defined by the techno-economic application methods [17] and [18]. The proposed method is based on power sharing strategy.

This paper deals with the voltage standardization of DC voltage for buildings. It starts with the discussion of the system configuration for both ACDS and DCDS for buildings in Section II. Next Section III demonstrates he simulation results including the mathematical portions and graphical results of the simulated data. The Section IV concludes the finding and signification of the paper.

\section{SYSTEM CONFIGURATION}

A residential building with DC appliances is shown in Fig. 1 and Fig. 2 with AC and DC distribution system respectively. The building is supplied by the public utility (PU) and solar plant (SP) in both cases. The battery bank (BB) and electric vehicle (EV) are behave as load and power source in case of non-availability of PU, SPV, peak load and higher generation. There are total six load rooms in this building. The building load is distributed in all the six rooms as shown in Fig. 1 and Fig. 2. The electrical specifications of the loads are mention in Table I While the efficiency of internal AC-DC converter of appliances is mention in Table I. As shown in Table I there are voltage ratings variation according to the type of load. $12 \mathrm{~V}$ rating available for very low load, medium load is captured under $24 \mathrm{~V}$ and for very high load like electric cars the voltage rating goes up to $96 \mathrm{~V}$. The AC-DC efficiency varies from $78 \%$ to $90 \%$ according to Table I. It can be noted that higher the converter power rating high is the AC-DC efficiency, as the highest efficiency $90 \%$, is in the case of hybrid car with converter power of rating 3000 Watt and lower efficiency $78 \%$, is in the case of cell phone with converter power of the rating of $4 \mathrm{Watt}$.
TABLE I: DESCRIPTION OF APPLIANCES AND AC-DC CONVERTER IN INDIA

\begin{tabular}{|c|c|c|c|c|c|}
\hline Appliance Name & $\begin{array}{c}\text { Type of } \\
\text { Supply }\end{array}$ & $\begin{array}{c}\text { Voltage } \\
\text { Rating } \\
\text { (Volt) }\end{array}$ & $\begin{array}{c}\text { Current } \\
\text { Rating } \\
\text { (Ampere) }\end{array}$ & $\begin{array}{c}\text { Power } \\
\text { Rating } \\
\text { (Watt) }\end{array}$ & $\begin{array}{c}\text { AC-DC } \\
\text { Converter } \\
\text { Efficiency } \\
{[19]-[20]}\end{array}$ \\
\hline LED Bulb & DC & $12 \mathrm{~V}$ & 0.6 & 7 & 0.79 \\
\hline CFL Bulb & DC & $12 \mathrm{~V}$ & 1.0 & 12 & 0.79 \\
\hline Electric Geyser & DC & $96 \mathrm{~V}$ & 10.5 & 1000 & 0.89 \\
\hline Sandwich Maker & DC & $24 \mathrm{~V}$ & 23.0 & 550 & 0.87 \\
\hline Water Purifier & DC & $24 \mathrm{~V}$ & 0.5 & 11 & 0.79 \\
\hline Refrigerator & DC & $24 \mathrm{~V}$ & 3.0 & 72 & 0.87 \\
\hline Coffee Maker & DC & $12 \mathrm{~V}$ & 11.0 & 135 & 0.87 \\
\hline Washing Machine & DC & $24 \mathrm{~V}$ & 3.0 & 70 & 0.86 \\
\hline Water Pump & DC & $24 \mathrm{~V}$ & 14.9 & 350 & 0.87 \\
\hline Vacuum Cleaner & DC & $12 \mathrm{~V}$ & 8.0 & 95 & 0.87 \\
\hline Air Conditioner & DC & $24 \mathrm{~V}$ & 33.30 & 800 & 0.88 \\
\hline Hybrid Car & DC & $96 \mathrm{~V}$ & 32.0 & 3000 & 0.9 \\
\hline Cell Phone & DC & $12 \mathrm{~V}$ & 0.3 & 4 & 0.78 \\
\hline Ceiling Fan & DC & $12 \mathrm{~V}$ & 1.70 & 20 & 0.83 \\
\hline Hair Drier & DC & $24 \mathrm{~V}$ & 15.0 & 425 & 0.87 \\
\hline TV & DC & $12 \mathrm{~V}$ & 2.5 & 30 & 0.83 \\
\hline Computer & DC & $12 \mathrm{~V}$ & 14 & 170 & 0.87 \\
\hline
\end{tabular}

\section{A. AC Distribution System (ACDS) for Buildings}

In this case, each line has a single voltage level of $230 \mathrm{~V}$ AC. The DC compatible loads are more efficient than the AC compatible load [3]. It is also assumed that each appliance is DC compatible which helps to reduce the building load as compare to the AC compatible load. Moreover each appliance has own internal AC-DC converter to connect with AC line, which add further losses. The converters efficiency is as mention in Table I. The total power consumption in buildings for $\operatorname{ACDS}\left(P_{A B C}\right)$ is the summation of power consumed by appliances $\left(P_{A}\right)$ and power losses in converters $\left(P_{C}\right)$. This expression is as below:

$$
P_{A C B}=P_{A}+p_{C}
$$

where $P_{A}=\sum_{j=1}^{n} P_{a j}$ and $P_{a j}$, is the power consumed by $j$ th appliance, while the total converter losses $\left(p_{c}\right)$ is the addition of power consumed in internal converters of appliances $\left(p_{a, c}\right)$ and source converter $\left(p_{s, c}\right)$ as express:

$$
p_{C}=\sum_{j=1}^{n} p_{a, c j}+\sum_{k=1}^{s} p_{s, c k}
$$

where $p_{a, c j}$ is the power losses in converter. $n$, total number of appliances and $s$, number of power source or storage in the residential building.

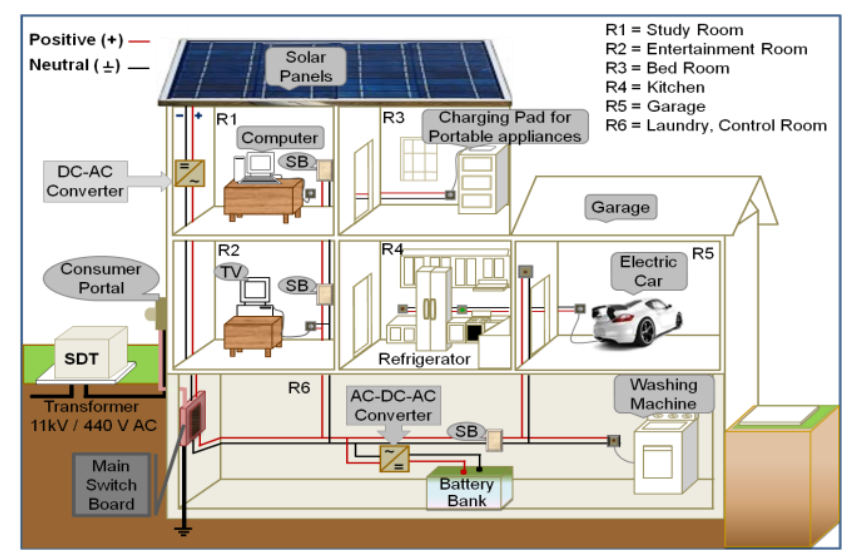

Fig. 1. AC distribution system for residential building. 


\section{PRoposed DC DISTRIBUTION SYSTEM}

In this case, it is also assumed that each appliance is DC compatible which helps to reduce the building load as compare to the AC compatible load. The selection of the cable is based on the ampacity [21]. The main DC bus has 24 volt voltage level. Moreover one boost DC-DC converter to step up the voltage level from 24 volt to 96 volt and supply electric car and electric geyser. While to supply the appliance of 12 volt, a buck DC-DC converter is connected to tie 24 volt to 12 volt DC bus. The appliances of 12 volt such as CFL, LED, Computer, TV, etc are directly connected to 12 volt DC bus while remaining 24 volt appliances are connect to main DC bus of 24 volt as shown in Fig. 2. The total power consumption in buildings for DCDS $\left(P_{D C B}\right)$ is the summation of power consumed by appliances $\left(P_{A}\right)$ and power losses in DC-DC and AC-DC converters $\left(p_{C}\right)$. This expression is as below:

$$
P_{D C B}=P_{A}+\sum_{k=1}^{m} p_{c k}
$$

where $m=3$ the number of converters in DC buildings.

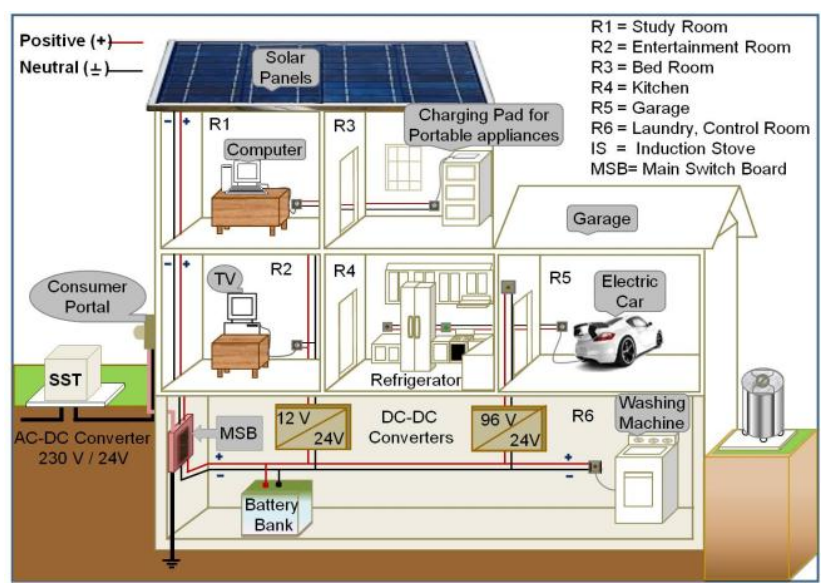

Fig. 2. Proposed DC distribution system for residential building.

\section{Simulation Results}

To study the dynamic power sharing strategy and investigate the system performance, the battery bank (BB), solar panel and public utility (PU) hybrid power system for residential building is simulated in MATLAB ${ }^{\mathrm{TM}}$. The battery is configured as 12 cells in series and 12 cells in parallel. The $1.28 \mathrm{~kW}$ plant and $1.56 \mathrm{~kW}$ with a 24 volt rated voltage solar plant (SP) is consider for DC distribution system (DCDS) and $\mathrm{AC}$ distribution system (ACDS). The PU is tied to consumer portal via AC-DC converter and step down transformer (SST) to 24 volt DC bus and 230 volt AC for DCDS and ACDS respectively. In both DCDS and ACDS case distribution line of power system are considered as lossless.

The power consumption in the building for ideal, DCDS and ACDS case has been shown in Fig. 3. The ideal case represents the power consumption in the appliances of the building represented by blue star at different instant of the curve. The ACDS load consists of power consumed by appliances, DC-AC and AC-DC conversion losses in the appliances the internal converter and sources converter represented by red curve. While the DCDS load includes the ideal load and DC-DC boost and buck converters and represented by green curve.

Fig. 3 represents the comparative analysis of power consumption in appliances, DCDS and ACDS. The building load is supplied by the PV plant during 9:30:00-12:30:00 time interval. In this interval only refrigerator ( 24 volt) is ' $\mathrm{ON}$ ' mode and $\mathrm{BB}$ remain in charging mode while other appliance remains in 'OFF' mode. The power consumption in DCDS is same as ideal case and the converter losses remain zero in this interval as shown in Fig. 6 by green line. The power equation for DCDS can be expressed as:

$$
P_{p v}=P_{b b}+\sum_{j=1}^{n} P_{a j}
$$

On the other hand for ACDS in the same time interval three type of converters such as DC-AC for PV Plant, AC-DC for $\mathrm{BB}$ and appliance internal AC-DC converter remain in ' $\mathrm{ON}$ ' mode and the average power losses is approximately 110 watt while the building ideal load is 72 watt. The power equation can be expressed as:

$$
P_{b b}=P_{p v}-\left(\sum_{j=1}^{n} P_{a j}+\sum_{j=1}^{n} p_{a, c j}+\sum_{k=1}^{s} p_{s, c k}\right)
$$

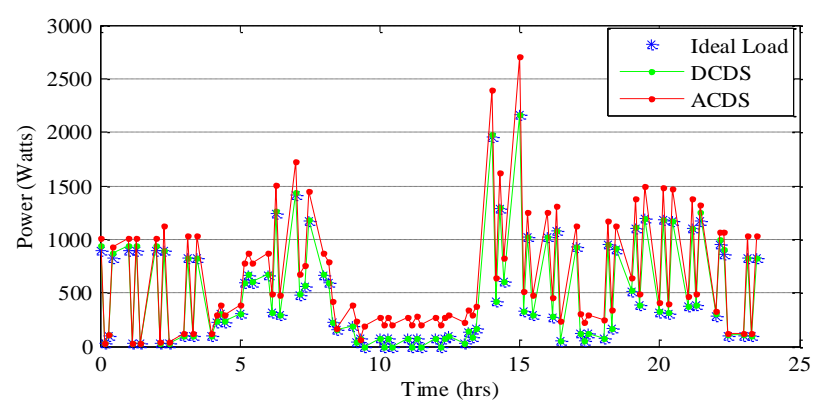

Fig. 3. Building load with ideal, ACDS and DCDS.

The power consumption from photovoltaic (PV) and public utility (PU) for ACDS and DCDS by red, green and blue, cyan color line respectively is shown in Fig. 4. The building is supplied by PU for both cases during 24:00 to 2:00 and 21:45 to 23:00 while PV and BB remain in isolated mode.

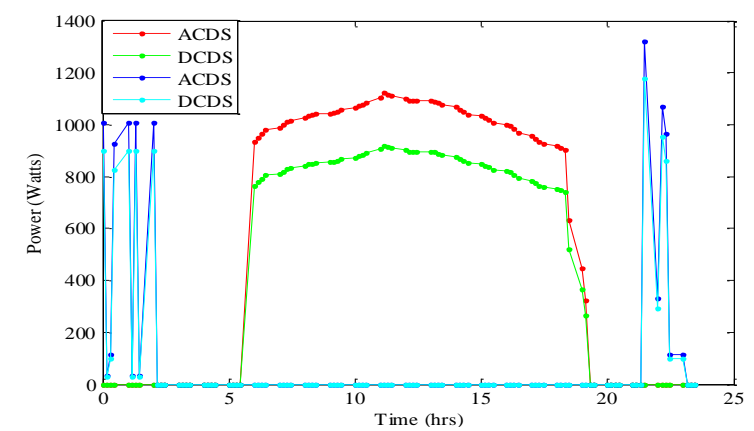

Fig. 4. Power consumed from PV and PU with DCDS and ACDS.

In ACDS the PU power consists of power consumption in appliances and internal converter of the appliances. The power equation can be expressed as: 


$$
P_{p u}=\sum_{j=1}^{n}\left(P_{a j}+p_{a, c j}\right)
$$

In DCDS the PU power consists of power consumption in appliances, solid state transformer (SST), and buck 24/12 volt and boost 24/96 volt converter of lines. The power equation can be expressed as:

$$
P_{p u}=\sum_{j=1}^{n} P_{a j}+\sum_{r=1}^{z} p_{l, c r}
$$

The PV output is higher than the building load during 6:00-6:15, 7:15-7:30, 8:00-13:45, and 17:15-18:00 time interval including with the instant $6: 45,14: 15,14: 45,15: 15$, $15: 45,16: 15,16: 45$ and 18:30. The PV plant is take care the building load and balance power is injected to $\mathrm{BB}$ as shown in Fig. 5. The power consumption for ACDS is the combination of sources converters including with ideal load and appliances converters. The power equation can be expressed as:

$$
P_{p v}=P_{b b}+\sum_{j=1}^{n} P_{a j}+\sum_{j=1}^{n} p_{a, c j}+\sum_{k=1}^{s} p_{s, c k}
$$

The power consumption for DCDS is the combination of power consumed in ideal load and power losses in the line converters. The power equation can be expressed as:

$$
P_{p v}=P_{b b}+\sum_{j=1}^{n} P_{a j}+\sum_{r=1}^{z} p_{l, c r}
$$

The PV output is less than the building load during 18:45-19:15 time interval including with the instant 6:30, $7: 00,7: 45,14: 00,14: 30,15: 00,15: 30,16: 00$ etc. The building load is partially supplied by the BB as shown in Fig. 5. The power consumption for ACDS is the combination of sources converters including with ideal load and appliances converters. The power equation can be expressed as:

$$
P_{p v}+P_{b b}=\sum_{j=1}^{n} P_{a j}+\sum_{j=1}^{n} p_{a, c j}+\sum_{k=1}^{s} p_{s, c k}
$$

The power equation for DCDS can be expressed as:

$$
P_{p v}+P_{b b}=\sum_{j=1}^{n} P_{a j}+\sum_{r=1}^{z} p_{l, c r}
$$

where $P_{b b}$ and $P_{p v}$ are the BB power and solar power respectively. $z$ and $n$ is the number of appliances and line converter respectively. During 2:15-5:45 and 19:30-21:30 time interval the building load is completely supplied by the $\mathrm{BB}$ and the power consumed from BB for ACDS, DCDS is shown in Fig. 5.

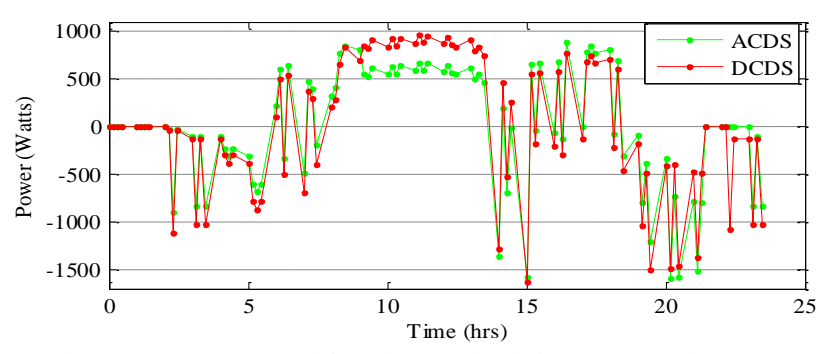

Fig. 5. Power consumed from battery bank for ACDS and DCDS.

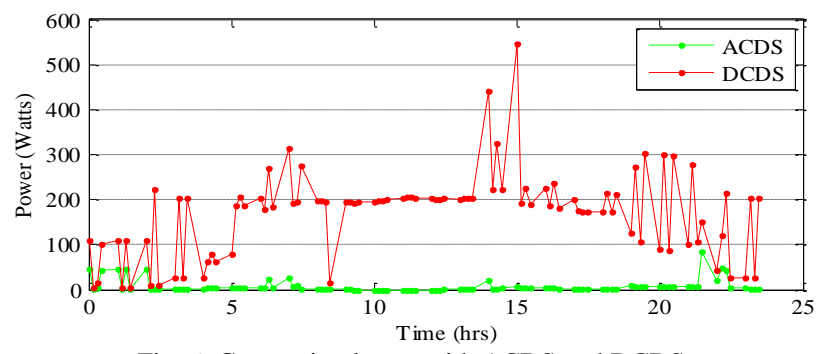

Fig. 6. Conversion losses with ACDS and DCDS.

In this case the power consumed for ACDS from BB consist of power consumed by appliance with internal AC-DC converter and power loss $\left(p_{b, c}\right)$ in $\mathrm{AC}-\mathrm{DC}$ converter of $\mathrm{BB}$. The power equation can be expressed as:

$$
P_{b b}=\sum_{j=1}^{n} P_{a j}+\sum_{j=1}^{n} p_{a, c j}+p_{b, c}
$$

For the above case the power consumed for DCDS from $\mathrm{BB}$ consist of power consumed by appliance and power loss in DC-DC converter of line. The power equation can be expressed as:

$$
P_{b b}=\sum_{j=1}^{n} P_{a j}+\sum_{r=1}^{z} p_{l, c r}
$$

The converter losses for ideal, DCDS and ACDS by blue, green and red line has been shown in Fig. 6. The converter losses for ideal system remain zero thought the day. In time interval 19:30 to 5:45 the SP output is zero as shown in Fig. 4. At 21:45 time instant the battery is not able to take care the building load of 1234.76 watt and remain in isolated mode while the load is supplied by the PU then DCDS has highest conversion losses of 64.758 watt. Moreover for the ACDS, at the 15:00 instant the building load of 2629.78 watt is partially supplied by the PV and BB has highest converter losses of 470.78 watt. These losses are the combination of converter losses of PV, BB converter and internal converter of appliances.

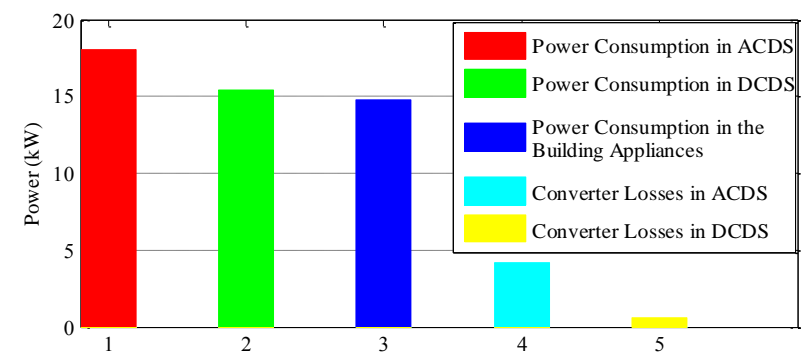

Fig. 7. Power consumption in the building in a typical day. 
Fig. 7, represent the total power consumed in the building for ideal, DCDS and ACDS by blue, green and red bar respectively for a typical day. Total power loss in the converter are represented by the cyan and yellow bar for ACDS and DCDS respectively. In the ideal case the total power consumption in the building is $46.52 \mathrm{~kW}$. In DCDS and ACDS the power consumption is $47.22 \mathrm{~kW}$ and $58.61 \mathrm{~kW}$. The conversion loss in DCDS is $0.71 \mathrm{~kW}$ while ACDS has $12.10 \mathrm{~kW}$ approximate 17 times higher than the DCDS losses.

\section{CONCLUSIONS}

The present paper demonstrates the different configurations for both ACDS and DCDS systems. A power system strategy based approach is used for the voltage standardization. This approach enables development of energy efficient economic and flexible LVDC systems and voltage standardization. Comparative analysis of ACDS and DCDS shows the superiority DCDS system off-course in terms of energy saving. Simulation results shows that the power consumed in DCDS systems is less than power consumed in ACDS system. However converter losses are much less in case of DCDS comparative to ACDS system.

\section{ACKNOWLEDGEMENT}

Authors are thankful to DST-UKIERI for the financial support.

\section{REFERENCES}

[1] M. Starke, L. M. Tolbert, and B. Ozpineci, "AC vs. DC distribution: A loss comparison," in Proc. IEEE Conf. and Exhibition on Transmission and Distribution, 2008, pp. 1-7.

[2] R. K. Chauhan, B. S. Rajpurohit, S. N. Singh, and F. M. Gonzalez-Longatt, "DC grid interconnection for conversion losses and cost optimization," Renewable Energy Integration, Green Energy and Technology, Springer Singapore, 2014, ch.14, pp. 327-345.

[3] K. W. E. Cheng, "Overview of the DC power conversion and distribution," Asian Power Electronics J., vol. 2, no. 2, pp. 75-82.

[4] R. K. Chauhan, B. S. Rajpurohit, and N. M. Pindoriya, "DC power distribution system for rural applications" in Proc. $8^{\text {th }}$ National Conf. on Indian Energy Sector, 2012, pp. 108-112.

[5] T. Gruzs, "Powering telecom and info technology systems," Power Quality Assurance, pp. 22-29, April 2001.

[6] J. Ciezki and R. Ashton, "Selection and stability issues associated with a navy shipboard DC zonal electric distribution system," IEEE Trans. Power Delivery, vol. 15, no. 2, pp. 665-669, April 2000.

[7] R. Hill, "Electric railway traction part 3 traction power supplies," Power Engineering Journal, vol. 8, pp. 275-286, Dec. 1995

[8] D. Nilsson and A. Sannino, "Load modelling for steady-state and transient analysis of low voltage DC system," in Proc. 39th IAS Annual Meeting IEEE Industry Applications Conf., 2004, pp. 774-780.

[9] M. Amin, Y. Arafat, S. Lundberg, and S. Mangold, "Low voltage DC distribution system compared with $230 \mathrm{~V}$ AC," in Proc. IEEE Electrical Power and Energy Conf., 2011, pp. 340-345.

[10] K. Engelen, E. L. Shun, P. Vermeyen, I. Pardon, R. Dhulst, J. Driesen, and R. Belmans, "Small scale residential DC distribution systems," in Proc. $3^{\text {rd }}$ IEEE Benelux Young Researchers Symposium in Electrical Power Engineering, 2006, pp. 1-7.

[11] P. Savage, R. R. Nordhaus, and S. P. Jamieson, "DC microgrids: Benefits and barriers," From Silos to Systems: Issues in Clean Energy and Climate Change, New Haven, CT: Yale Publications, 2010.

[12] D. J. Hammerstrom, "AC versus DC distribution systems-did we get it right," in Proc. IEEE Power Engineering Society General Meeting, 2007, pp. 1-5.

[13] P. Paajanen, T. Kaipia, and J. Partanen, "DC supply of low voltage electricity appliances in residential buildings," in Proc. 20th International Conf. and Exhibition on Electricity Distribution, 2009, pp. 1-4.
[14] P. W. Lee, Y. Z. Lee, and B. T. Lin, "Power distribution systems for future homes," in Proc. IEEE International Conf. on Power Electronics and Drive Systems, 2009, vol. 2, pp. 1140-1146.

[15] K. Engelen, E. L. Shun, P. Vermeyen, I. Pardon, R. D. Hulst, J. Driesen, and R. Belmans, "The feasibility of small scale residential DC distribution systems," in Proc. IEEE Conf. on Industrial Electronics, 2006, pp. 2618-2623.

[16] E. Cetin, A. Yilanci, H. K. Ozturk, M. Colak, I. Kasikci, and S. Iplikci, "A micro DC power distribution system for a residential application energized by photovoltaic wind/fuel cell hybrid energy systems," Energy and Buildings, vol. 42, no. 8, pp. 1344-1352, August 2010.

[17] J. Lassila, T. Kaipia, V. Voutilainen, J. Haakana, J. Partanen, and K. Koivuranta, "Potential of power electronics in electricity distribution systems," in Proc. the Nordic Distribution and Asset Management Conf., 2008.

[18] T. Kaipia, J. Lassila, P. Salonen, V. Voutilainen, and J. Partanen, “A planning methodology for combined AC and DC electricity distribution networks," presented at Nordic Distribution and Asset Management Conf., 2008.

[19] K. Garbesi, V. Vossos, and H. Shen, "Catalog of DC appliances and power systems," Lawrence Berkeley National Laboratory, pp. 1-76, Oct. 2011.

[20] R. K. Chauhan and B. S. Rajpurohit, "DC Distribution System for Energy Efficient Buildings," in Proc. $18^{\text {th }}$ National Power System Conf., Dec. 18-20, 2014.

[21] P. E. Gershony and T. McCalmont. (2012). Optimal DC cable selection in PV designs. Solarpro. [Online]. pp. 64-73. Available: http://www.solarprofessional.com

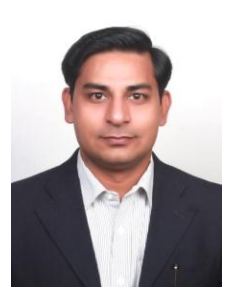

Rajeev Kumar Chauhan graduated in electrical engineering from the Institutions of Engineers, India. $\mathrm{He}$ received his M.Tech. degree in control and instrumentation engineering from Dr. B. R. Ambedkar National Institute of Technology Jalandhar, India. Presently, he is a research scholar with the School of Computing and Electrical Engineering at Indian Institute of Technology Mandi, India.

From July 2014-Oct. 2014, he was a visiting scientist in the Center for Electro-mechanics at the University of Texas at Austin, US. From 2011-2012, he was with the Department of Electrical and Electronics Engineering at Roorkee Institute of Technology, Roorkee as an assistant professor. He has also worked as a senior lecturer with the Department of Control and Instrumentation Engineering, Galgotias College of Engineering and Technology Greater Noida, in 2010-2011 and as a lecturer with the Department of Electrical and Electronics engineering at Krishna Engineering College Ghaziabad in 2009-2010. His research interests include DC microgrid and grid integration of renewable energy sources, SCADA system, industrial automation and control.

Mr. Chauhan is a reviewer of the IEEE Transaction on Sustainable Energy, the IEEE Transaction on Industrial Electronics, IEEE Systems Journal, IEEE Power and Energy Technology Systems Journal, Renewable \& Sustainable Energy Reviews, Elsevier, Journal of The Institution of Engineers (India)-A Series and Member of the Reviewer board of Engineering Letters, International Association of Engineers (IAENG), Hong Kong. Also he is a reviewer of ICMLC 2011, CSPA 2013, PESGM 2013-14.

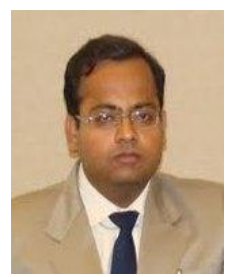

Bharat Singh Rajpurohit received the M.Tech. degree from the Indian Institute of Technology Roorkee, India and the Ph.D. degree from Indian Institute of Technology Kanpur, India. Presently, he is working as an assistant professor in the School of Computing and Electrical Engineering at Indian Institute of Technology Mandi, India. His research interests include power electronics and grid integration of renewable energy sources. He is a member of ISTE and IEEE.

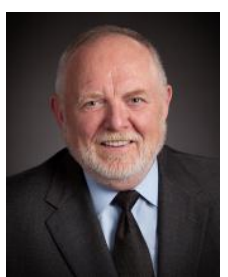

Robert E. Hebner joined the University of Texas at Austin in 1999. He is the director of the Center for Electro-mechanics. The center focuses on the production, conversion, and storage of power and energy. Prior to joining UT, Dr. Hebner was an acting director of the National Institute of Standards and Technology (NIST), an agency of the U.S. Department of Commerce. He also served as the deputy director of NIST, the chief financial officer of NIST, and the director of NIST's Electronics and Electrical Engineering Laboratory. Dr. 
Hebner also worked in the Office of Management and Budget, where he helped prepare the technology portions of the Administration's 1990 budget; at Sandia, where he worked in accelerator design; and at the Advanced Research Projects Agency of the Department of Defense, where he developed programs to stimulate technical advances in semiconductor manufacturing. He has served on a number of government review teams to assess the management of technical programs in other organizations. He was the principal investigator and the government's key witness in a celebrated court case involving an alleged novel approach to the efficient generation of electricity.

Dr. Hebner has had extensive experience in international technology programs, particularly in the areas of modernization of the measurement systems needed to support global trade. He was responsible for the modernization and operation of the watthour meter calibration service that serves as the reference for all electricity metering in the United States. Throughout his career, Dr. Hebner has been active in technical activities having received a $\mathrm{Ph} . \mathrm{D}$. degree in physics and having authored or coauthored more than 115 technical papers and reports. He is a past president of the Dielectrics and Electrical Insulation Society of the Institute of Electrical and Electronics Engineers. In addition, he has served on numerous technical committees that develop voluntary standards for the electric utility industry.

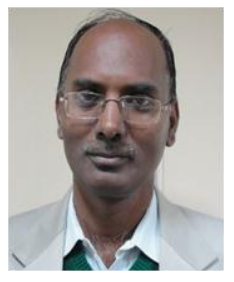

S. N. Singh received the Ph.D. degree in electrical engineering from the Indian Institute of Technology Kanpur, India, in 1995 . He is currently a professor with the Department of Electrical Engineering, Indian Institute of Technology Kanpur. His research interest include power system restructuring, FACTS, power system optimization and control, security analysis, and power system planning. Prof. Singh is a fellow of the IETE and the Institution of Engineers, India.

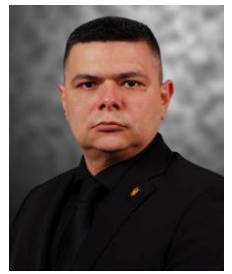

Francisco M. Gonzalez-Longatt is currently a lecturer in electrical power system at the Electrical Power System en School of Electronic, Electrical and Systems Engineering Loughborough University. His academic qualifications include the first class for electrical engineering of Instituto Universitario Politécnico de la Fuerza Armada Nacional, Venezuela, 1994, the master of business administration (honors) degree from Universidad Bicentenaria de Aragua, Venezuela, 1999 and the $\mathrm{PhD}$ degree in electrical power engineering from Universidad Central de Venezuela, 2008. He is an former associate professor in 1995-2009, and the chair (in 1999-2001) of the Department of Electrical Engineering of Universidad Nacional Politécnico de la Fuerza Armada Nacional, Venezuela, from 1995 to 2009. He is the author or editor of several books (Spanish and English) including Power Factory Applications for Power System Analysis, Springer, 2014. He is the vice-president of Venezuelan Wind Energy Association, a senior member of the Institute of Electrical and Electronic Engineering (IEEE), a member of The Institution of Engineering and Technology - The IET (UK) and a member of International Council on Large Electric Systems - CIGRE. He received the professional recognition as FHEA - Fellow of the Higher Education Academy in January 2014. His research interest includes innovative (operation/control) schemes to optimize the performance of future energy systems. His research is or has been supported by Royal Society - UK. Two special research projects financially supported by the Royal Society deserve mention: "Smart multi-terminal DC $\mu$-grids for autonomous zero-net energy buildings," and "Exploring beyond the frontiers to build a smarter grid (EBF2BSG)", 